\title{
Cortical EEG correlates of successful memory encoding: Implications for lifespan comparisons
}

\author{
Markus Werkle-Bergner*, Viktor Müller, Shu-Chen Li, Ulman Lindenberger \\ Max Planck Institute for Human Development, Center for Lifespan Psychology, Lentzeallee 94, 14195 Berlin, Germany
}

\begin{abstract}
In the course of their lives, individuals experience a myriad of events. Some of them leave stable traces, and others fade away quickly. Recent advances in functional imaging methods allow researchers to contrast neuronal patterns of remembered against not remembered events at initial encoding. Research on young adults using functional magnetic resonance imaging (fMRI), intracranial, and standard electroencephalographic (EEG) recordings has identified differences between remembered and not remembered items in patterns of medio-temporal and prefrontal brain activity. However, little is known about the ways in which such neuronal patterns of successful encoding evolve across the lifespan as a function of maturation, senescence, and the accumulation of experience. Here, we first review empirical evidence on neuronal correlates of successful memory from middle childhood to old age. Based on the observation that associative and strategic components of episodic memory seem to follow different age gradients, we propose a conceptual framework for predicting age changes in neuronal patterns of successful encoding.
\end{abstract}

(C) 2006 Elsevier Ltd. All rights reserved.

Keywords: Subsequent memory effects; Development; Aging; Lifespan; Memory; EEG; Synchronization; Oscillations

\section{Contents}

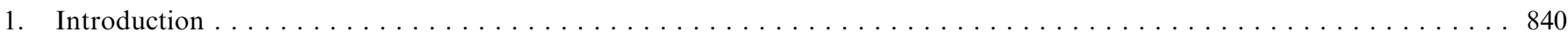

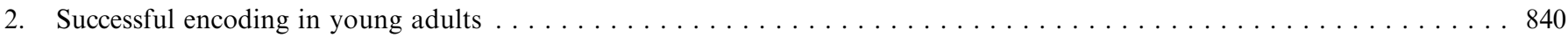

2.1. Studying successful memory encoding with the subsequent memory paradigm $\ldots \ldots \ldots \ldots$

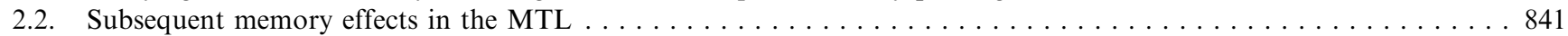

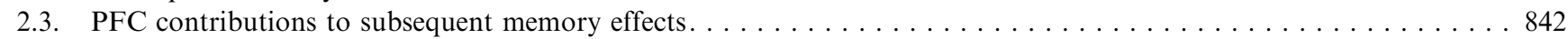

2.4. Linking functional neuroanatomy and temporal dynamics: EEG correlates of successful encoding . . . . . . . . 843

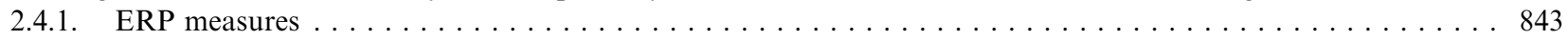

2.4.2. EEG measures of coherence and synchronization $\ldots \ldots \ldots \ldots \ldots \ldots$

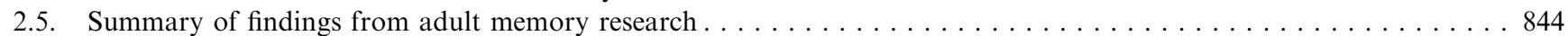

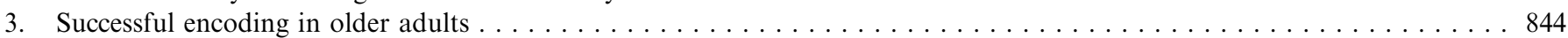

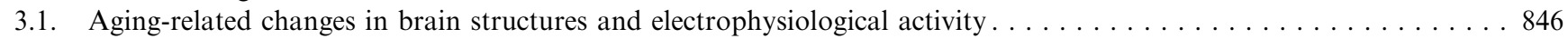

3.2. Aging and subsequent-memory effects: fMRI and PET findings $\ldots \ldots \ldots \ldots$

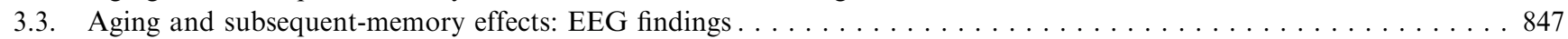

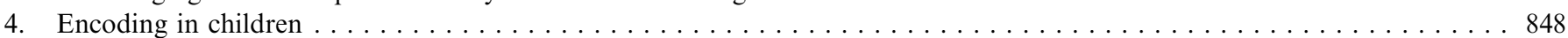

4.1. Maturational changes in brain structures and electrophysiological activity $\ldots \ldots \ldots \ldots$

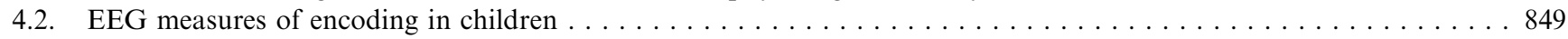

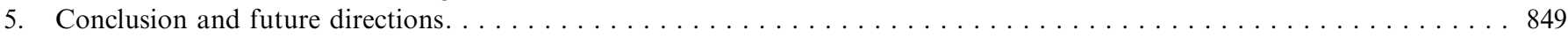

5.1. Lifespan changes in subsequent memory effects: comparing PFC and MTL structures . . . . . . . . . . . . 849

\footnotetext{
*Corresponding author. Tel.: + 493082406447 ; fax: +493082406571.

E-mail address: werkle@mpib-berlin.mpg.de (M. Werkle-Bergner).
} 
5.2. Investigating lifespan differences in neuronal organization of successful encoding $\ldots \ldots \ldots 50$

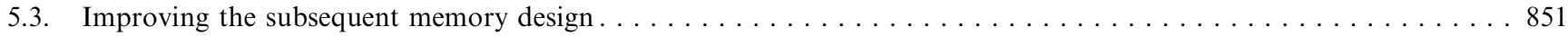

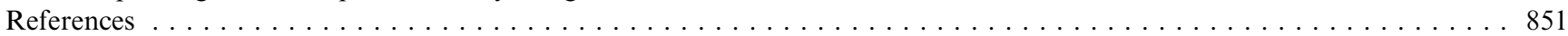

\section{Introduction}

The events we experience in the course of our lives fall into two general categories: those we remember and those we do not. Some events will enter and persist in our memories; others will be hardly noticed, or, if noticed, forgotten. Cognitive neuroscientists have intensified their efforts to identify mechanisms that relate the memory fate of our experiences to operations of encoding, storage, and retrieval (Squire, 1987; Tulving, 1983). Encoding and retrieval are closely intertwined, as new experiences trigger and transform old memories, and vice versa. At the same time, for any new-experienced event, encoding precedes storage without implying it, and storage precedes retrieval without implying it. Perhaps reflecting this asymmetry, most studies have focused on the encoding phase when trying to predict the memory status of experience.

In adult memory research, new methods for studying cortical correlates of successful encoding have been developed in recent years. Functional magnetic resonance imaging (fMRI) and diffusion tensor imaging (DTI) permit the identification of functional brain circuitry and structural connectivity among brain regions that contribute to effective memory formation. Available evidence suggests that successful memory encoding operations involve distributed neural networks across multiple brain regions (e.g., Fuster, 1995; Varela et al., 2001; see Paller and Wagner, 2002 for a recent review). In fMRI-based research, some consensus has been reached about the functional neuroanatomical correlates of memory encoding. However, the nature and time course of dynamic interactions among brain regions that contribute to encoding efficacy remain largely unknown. Methods with higher temporal resolution than current fMRI, such as electroencephalographic (EEG) recordings, are needed to shed light on the time course of encoding-relevant brain dynamics (e.g., Dixon et al., 2004; Klimesch, 1999; Kounios et al., 2001; Summerfield and Mangels, 2005).

The individual's ability to successfully remember past events is subject to profound lifespan changes (Baltes et al., 2006a; Dixon et al., 2004; Gathercole, 1998). Relatedly, various brain regions supporting encoding operations undergo substantial neurochemical (see Bäckman and Farde, 2005; Benes et al., 2000 for reviews), anatomical (Giedd et al., 1999; Raz, 2005; Simons and Spiers, 2003 for reviews), and functional (see Cabeza, 2002; Johnson, 2001 for reviews) changes throughout life. Thus, it can be expected that cortical functional circuitries and temporal dynamics underlying successful memory encoding may differ between predominantly developing, mature, and aging neurocognitive systems. Some studies have investi- gated adult lifespan differences in structural and functional correlates of episodic memory encoding (Daselaar et al., 2003; Daselaar et al., 2003; Grady et al., 2003; Grady et al., 1999; Stebbins et al., 2002). Generally, however, age comparisons of functionally relevant neuroanatomical regions and their cortical dynamics are lacking.

This article has three major goals: (i) to review recent methodological advances in adult memory research on successful encoding, with a particular emphasis on brain electrophysiological methods that are particularly apt for studying temporal dynamics of encoding operations; (ii) to highlight currently available evidence on cortical correlates of memory encoding from adult and child developmental literatures; and (iii) to outline possible avenues for future neurocognitive research on age differences in brain correlates of successful encoding.

\section{Successful encoding in young adults}

Encoding refers to operations that initiate the later formation of a memory trace. Some researchers have suggested that at least two interrelated but distinct component processes are involved in transforming sensory inputs into more durable memory representations (Miller, 1991; Nolde et al., 1998). First, multi-sensory inputs of a memory episode that are processed by different brain regions need to be transformed and bound together into cohesive internal representations via mechanisms of temporal synchronization (Engel and Singer, 2001; TallonBaudry and Bertrand, 1999) and conjunctive coding (e.g., Barlow, 1972; O'Reilly and Norman, 2002; O'Reilly and Rudy, 2001). Second, the resulting perception-based internal representations need to be associated with representations of already existing knowledge and contextual information. Thus, perceptual and conceptual features as well as contextual details and self-generated thoughts that pertain to the current episode need to be co-activated during encoding to give rise to new memories.

\subsection{Studying successful memory encoding with the subsequent memory paradigm}

In adult memory research, neural mechanisms underlying successful encoding are often studied with the 'subsequent memory paradigm' (Fig. 1). In this paradigm, neural activities in response to distinct stimuli are recorded while individuals are explicitly or implicitly engaged in learning the stimuli for an upcoming memory test. Afterwards, the stimuli are classified based on whether they were remembered or not. It is generally accepted that differences in neural activities resulting from contrasting remembered 
(a)

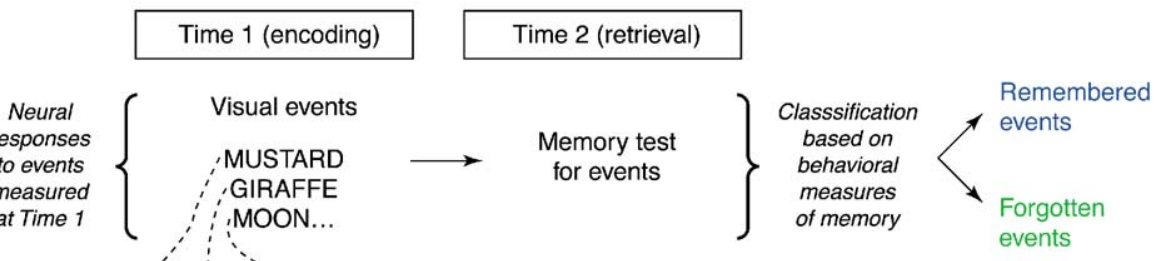

(b) Events at

Time 1
classified;

responses

extracted

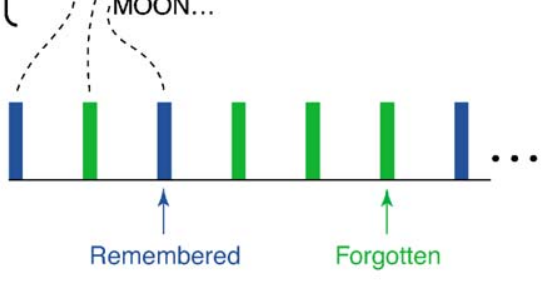

Remembered

Forgotten
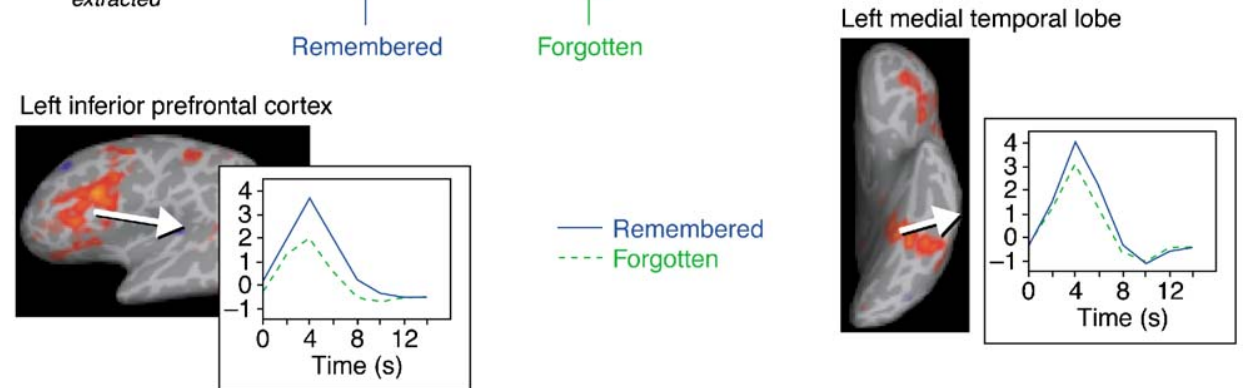

Fig. 1. Schematic depiction of the subsequent memory paradigm. (a) Neural activity is recorded while people encode information. Later, events are classified according to memory performance. (b) Neural responses differ for correctly remembered or not remembered items. Here, remembered events (blue) elicited greater fMRI responses than not remembered events (green). (Reprinted with permission from Paller and Wagner, 2002.)

against not remembered items indicate neural activity during the time of encoding that is predictive of accurate recall or recognition (Differential neural activity predicting memory, or Dm; Paller et al., 1987). Generally, activity levels at encoding are higher for remembered items than for not remembered items.

Neuroimaging studies point to the importance of the medial-temporal lobes (MTL) and lateral prefrontal cortex (PFC) in encoding-related activities e.g., (Brewer et al., 1998; Canli et al., 2000; Fell et al., 2003; Fernàndez et al., 1999b; Kelley et al., 1998; Kirchhoff et al., 2000; Mangels et al., 2001; Otten et al., 2001, 2002; Paller et al., 1987; Sanquist et al., 1980; Stebbins et al., 2002; Tulving et al., 1994; Wagner et al., 1999, 1998a, b; Weiss and Rappelsberger, 2000). Differential contributions of various structures in the MTL (e.g., hippocampus, parahippocampus, rhinal cortices) and the PFC (e.g., lateral, medial, ventral, dorsal PFC) to successful encoding appear to depend on the type of learning materials (e.g., verbal vs. pictorial), encoding intentionality (incidental vs. effortful), and the nature of the task (e.g., item vs. associative memory). In the following, subsequent memory effects observed in MTL and PFC regions are reviewed separately.

\subsection{Subsequent memory effects in the $M T L$}

Regions in the MTL, and the hippocampus in particular, play a critical role in memory formation (Scoville and Milner, 1957). Several human neuroimaging studies have reported subsequent memory effects in distinct MTL regions, such as rhinal cortices (e.g., Fernàndez et al., 1999a, b; Strange et al., 2002), parahippocampal cortex (e.g., Brewer et al., 1998; Kirchhoff et al., 2000; Wagner et al., 1998b), hippocampus (e.g., Kirchhoff et al., 2000; Otten et al., 2001), and amygdala (Canli et al., 2000). Evidence from animal studies indicates that cortical processing in MTL regions follows a hierarchical organization in accordance with corresponding anatomical connections and fibre projections (Brown and Aggleton, 2001). Unimodal and polymodal association areas project sensory inputs primarily via perirhinal and parahippocampal cortices into the MTL. Further efferents from both structures project to the enthorhinal cortex, which in turn enervates the hippocampus. In light of this sequential processing hierarchy, it has been suggested that perirhinal and parahippocampal areas are relatively more involved in perception-based encoding processes, whereas hippocampal processing allows for more flexible and contextually integrated forms of binding (Brown and Aggleton, 2001; Eichenbaum, 2000; O'Reilly and Norman, 2002; Suzuki, 1999).

A major portion of subsequent memory has investigated whether neural processes are modulated by the specifics of the to-be-remembered materials such as verbal vs. pictorial material (cf. Paller and Wagner, 2002). Material-specific lateralization in the MTL has been shown in some studies. Extant findings indicate (a) that subsequent memory for incidentally learned verbal materials (e.g., words) is primarily associated with left lateralized MTL activation (Golby et al., 2001; Kirchhoff et al., 2000; Opitz et al., 2000; Wagner et al., 1998b), (b) that memory for figural materials is associated with bilateral hippocampus/MTL activation (e.g., Golby et al., 2001; Kelley et al., 1998), and (c) that memory for spatial materials (e.g., scenes, faces, or 
visuo-spatial patterns) is associated with right MTL (and bilateral) activations (e.g., Golby et al., 2001; Kelley et al., 1998; Kirchhoff et al., 2000). Together, these results show that hippocampal/MTL memory operations during encoding are sensitive to the specific "modality" of to-beremembered items.

In addition to modality specificity, converging evidence suggests that the hippocampus is specialized for associative, particularly relational memory, binding (Davachi and Wagner, 2002; Jackson and Schacter, 2004; Zeineh et al., 2003). For instance, (Davachi and Wagner, 2002) presented word triplets and contrasted two verbal encoding conditions. In an item-based condition, participants rehearsed the three items in the order presented, whereas in a relational condition, participants were required to internally reorder the items as a function of desirability. Encoding-related activity in the hippocampus was greater in the relational as compared to the item-based condition, whereas the reversed comparison revealed superior activation in entorhinal and parahippocampal cortex. Subsequent memory effects in the hippocampus were restricted to relationally encoded stimuli. Similarly, (Jackson and Schacter, 2004) found that hippocampal activation during word-pair encoding predicted subsequent memory for interitem associations beyond memory for individual items.

Recent studies with intracranial EEG recording have further confirmed differential subsequent memory effects in distinct MTL regions. Fernàndez and colleagues (e.g., Fell et al., 2001, 2003; Fernàndez et al., 1999b) recorded eventrelated potentials (ERP) directly from the human medial temporal lobe using intracerebral electrodes in patients suffering from pharmacoresistant temporal lobe epilepsy. In these studies, ERPs were measured during the study phase while the patients were studying words. Later, ERPs were classified based on the participants' subsequent memory performance in a free recall test. Compared to the forgotten words, remembered words elicited a negativity between 400 and $500 \mathrm{~ms}$ after stimulus onset in the anterior parahippocampal gyrus (rhinal cortex; AMTLN400; Fernàndez et al., 1999b) and more positive activity in the hippocampus in the time window between 500 and $2000 \mathrm{~ms}$ after stimulus onset. These data suggest that both the rhinal cortex and the hippocampus are implicated in the formation of episodic memories, but with different time courses. To further examine the temporal dynamics between early rhinal and late hippocampal processes, (Fell et al., 2003) analyzed phase synchronization in the gammafrequency range $(>30 \mathrm{~Hz})$ between rhinal and hippocampal electrodes. Subsequently remembered words elicited an early increase (100-300 and $500-600 \mathrm{~ms}$ after stimulus onset) and a late decrease $(1000-1100 \mathrm{~ms})$ in phase synchronization between both MTL structures relative to not remembered items. Taken together, these studies suggest that successful memory encoding is positively related to dynamically synchronized interactions between the rhinal cortex and the hippocampus, with some temporal and functional specializations for either structure.

\subsection{PFC contributions to subsequent memory effects}

Patients with lesions restricted to the frontal lobes generally do not exhibit amnesic syndromes as severe and global as patients with lesions in MTL. Nevertheless, several studies show that memory performance is modulated by PFC activations during encoding. Similar to findings from the MTL regions, the laterality of such effects again depends on the type of encoding material. For instance, verbal material leads to memory-predicting activations primarily in left PFC (e.g., Kelley et al., 1998; Wagner et al., 1998b), whereas studying unfamiliar faces (e.g., Kelley et al., 1998) or pictures of natural scenes (e.g., Brewer et al., 1998) leads to activations in the right hemisphere (e.g., Opitz et al., 2000). Correspondingly, memorization of nameable objects often leads to bilateral activation patterns (e.g., Kelley et al., 1998).

Despite the "modality" specificity of PFC activations and early theoretical attempts to map lateralisation effects found in positron-emission tomography (PET) studies onto specific memory processes (hemispheric encoding/retrieval asymmetry model (HERA), e.g., Tulving et al., 1994), recent reviews (e.g., Duncan and Owen, 2000; Fletcher and Henson, 2001; Lee et al., 2000; Nolde et al., 1998) converge on the notion that PFC involvement during memory encoding reflects more general executive and working memory processes. Such views are in line with the observation that patients with frontal lobe lesions show severe deficits on tests tapping into working memory and executive functions without being amnesic (e.g., Fletcher and Henson, 2001; Lee et al., 2000). Furthermore, there is substantial overlap between the reported PFC activation patterns found in working memory/executive functions tasks and those observed in memory studies (e.g., see Duncan and Owen, 2000; Lee et al., 2000 for comparisons of activation sites in various tasks). Taken together, these findings are in accordance with theories that attribute a general regulatory/executive function to the PFC (e.g., generating goal-directed bias/gating signals that modulate processes in posterior sensory and association areas; Desimone and Duncan, 1995; Miller, 1991). Dense reciprocal connectivity within the PFC itself and to almost all posterior processing areas, including the MTL/diencephalon, is assumed to support these regulatory functions (Miller, 1991; Pandya and Yeterian, 1996; Petrides, 1994; Simons and Spiers, 2003). Hence, PFC activations during memory encoding are assumed to reflect control processes that aid and optimize memory encoding (e.g., Fletcher and Henson, 2001; Simons and Spiers, 2003). Memory-relevant functions of PFC activity during encoding may include (a) directing attention to relevant stimulus dimensions; (b) selecting, organizing, and elaborating to-be-learned information, in part by retrieving semantic attributes and associates from long-term memory, and (c) maintaining information in working memory. The specific contributions of different PFC sites to successful encoding and their interactions are currently not well understood. 


\subsection{Linking functional neuroanatomy and temporal dynamics: EEG correlates of successful encoding}

Successful encoding apparently relies on close interactions between sensory-specific and multimodal posterior association areas as well as flexible executive regions within the frontal lobes (e.g., Fletcher and Henson, 2001; Simons and Spiers, 2003). A more process-oriented understanding of cortical correlates of successful memory encoding thus requires evidence on the dynamical interplay among memory-relevant brain regions. To this end, functionally relevant interaction patterns among brain areas during encoding (Bressler, 2002; Nunez, 2000; Varela et al., 2001) need to be assessed with methods that yield high temporal resolution such as EEG recordings (e.g., Fell et al., 2001, 2003; Fernàndez et al., 1999b; Klimesch et al., 1996; Sederberg et al., 2003); for an earlier review, (cf. Klimesch, 1999). Intracranial recordings have revealed the functional relevance of oscillatory MTL activity for successful encoding (Fell et al., 2001, 2003; Fernandez and Tendolkar, 2001; Fernàndez et al., 1999b). In healthy individuals, noninvasive surface recording methods have to be used to generate comparable information.

\subsubsection{ERP measures}

The first studies that investigated EEG correlates of successful encoding used ERP to measure differences in neural processing associated with later remembered and not remembered stimuli. The main findings from these early studies suggest more positive ERPs for items that were remembered than for those that were not (e.g., Paller et al., 1987; Sanquist et al., 1980). ${ }^{1}$ More specifically, two classes of Dm effects were found: one with a centro-parietal maximum in the latency range of about $300-800 \mathrm{~ms}$, and another with a similar or even later onset and a maximum over frontal sites that typically lasts longer than the centroparietal effect for reviews (cf. Friedman, 1990; Paller and Wagner, 2002; Wagner et al., 1999). Interestingly, such frontal components were more pronounced when participants were explicitly instructed to remember (Friedman and Johnson, 2000; Münte et al., 1988). Also, frontal subsequent memory effects are modulated by contrasts between elaborative and rote rehearsal (Fabiani et al., 1990), between deep and shallow encoding (Sanquist et al., 1980), and between associative and non-associative encoding tasks (Kounios et al., 2001; Weyerts et al., 1997).

The dissociability of frontal and centro-parietal Dm effects points to neural generators in different brain regions that may serve distinct cognitive functions. Further information about functional differences between frontal and centro-parietal Dm effects is obtained by studies that failed to find parietal $\mathrm{Dm}$ effects under conditions of intentional encoding. For example, Münte et al. (1988)

\footnotetext{
${ }^{1} \mathrm{~A}$ few studies also reported Dm effects with negative polarity, primarily in response to auditory stimuli (Cycowicz and Friedman, 1999; Guo et al., 2005).
}

observed a broadly distributed subsequent memory effect with an early onset for items studied under incidental encoding conditions, with a maximum at $\mathrm{Cz}$ and $\mathrm{Pz}$. By contrast, the subsequent memory effect for intentional encoding conditions showed a later onset and was located more frontally $(\mathrm{Fz})$. Hence, frontal subsequent memory effects, presumably reflecting prefrontal activity, seem to be correlated with effortful encoding operations.

\subsubsection{EEG measures of coherence and synchronization}

A complementary approach for tracking neural correlates of successful encoding at the level of EEG recordings can be derived by observing patterns of oscillatory brain activity, or the presence of rhythmic activity in the EEG (Klimesch, 1999). Specifically, the theta rhythm has been found to be important for memory encoding (see Klimesch, 1996; Klimesch, 1999 for reviews). Long-term potentiation (LTP), the candidate cellular-molecular mechanism for the formation of enduring memory traces appears to be induced or at least enhanced through stimulation in the theta frequency range (Greenstein et al., 1988; Larson et al., 1986). Furthermore, LTP might be dependent on the phase angle of hippocampal theta activity (Huerta and Lisman, 1993) and blocking of theta activity by lesioning the medial septum seems to cause memory impairments (Givens and Olton, 1990).

Volume conduction from deep sources like the hippocampus, however, is unlikely to contribute to scalp recorded theta activity directly, but rather through hippocampal-neocortical feedback loops (Klimesch, 1996; Klimesch, 1999). This mechanism is likely to exist, given the vast reciprocal connections between MTL and neocortical regions (Miller and Cohen, 2001). In this vein, Klimesch et al. (1996) reported evidence suggesting that theta synchronization is important for successful encoding in human subjects. They observed event-related synchronization/ desynchronization (ERS/ERD) in individually adjusted theta and two alpha frequency bands as well as changes in absolute spectral power during the encoding phases of a word-recall memory task. By comparing ERS/ERD- and power-values for remembered and not remembered words, Klimesch et al. (1996) showed that theta frequency showed an event-related increase in ERS and exhibited higher spectral power values for later recalled words. In contrast, the alpha frequencies did not show differential event-related changes with respect to recall status. Similarly, Mölle et al. (2002) reported that efficient encoding, for words as well as faces, was characterized by an increase in theta synchronization conjoined with ERD in the upper alpha frequency band.

Based on an extensive review of relevant findings, Klimesch (1999) further argued that ERD in lower alpha bands $(\sim 8-10 \mathrm{~Hz})$ during encoding activities probably reflects general task demands and attentional processes, while desynchronization in the upper alpha band $(\sim 10-12 \mathrm{~Hz})$ correlates with the semantic processing of items. Therefore, it seems reasonable to conclude that 
changes in theta bands (probably related to LTP) and alpha bands (related to attentional and semantic processes) during memory encoding point to the involvement of distinct neuronal functional circuitries that cooperate in the course of mnemonic activity.

Summerfield and Mangels (2005) recently investigated integrative information processing in widespread networks throughout the cortex during memory encoding. They observed coherent fronto-posterior theta activity $(4.3-7.8 \mathrm{~Hz})$ during encoding of either item (WO) or itemplus-context encoding (WC) in a word recognition paradigm. Specifically, successful item encoding was characterized by sustained local theta activity over left frontal recordings and increases in long-range coherence within the left hemisphere, primarily between anterior frontal and posterior regions. In trials with successful item-plus-context encoding, additional early increases in theta power (approximately $400 \mathrm{~ms}$ post-stimulus) were observed over right frontal recordings along with later $(>800 \mathrm{~ms})$ increases in fronto-posterior coherence (Fig. 2).

In addition to complex patterns of theta and alpha band involvement during encoding, encoding-related activity also has been observed in the gamma frequency bands. For example, in a word recognition paradigm, Gruber et al. (2004) found an early (200-300 ms post-stimulus) widespread increase in whole gamma power that was associated with successful encoding. Interestingly, this gamma-band Dm effect preceded subsequent memory effects observed in the ERPs (300-900 ms post-stimulus). Similar results were reported by Sederberg et al. (2003), who recorded oscillatory brain activity during encoding from patients with subdural electrodes, surgically implanted on the cortical surface. They found positive subsequent memory effects in the theta $(4-8 \mathrm{~Hz})$ and gamma $(28-64 \mathrm{~Hz})$ frequency bands primarily at temporal and frontal electrodes. Whereas the theta activities were predominantly right lateralized, gamma activity exhibited a bilateral pattern.

These findings are of special interest in the light of computational models suggesting that the coupling of oscillatory networks in the theta and gamma range might underlie memory formation (Jensen, 2001; Lisman and Idiart, 1995). One model (Lisman and Idiart, 1995) assumes that memories are initiated by synchronized firing patterns of pyramidal neurons. The model further assumes that synchronous activity in neuronal assemblies tends to weaken over time and therefore needs to be refreshed regularly, and that individual memory components are refreshed at gamma frequency, whereas the entire memory episode is refreshed at theta frequency. Thus, the storage of multiple items in short-term memory is coded by distinct cycles of hippocampal gamma oscillations and their relative temporal correspondences to the phase of theta rhythm. In general support of this conjecture, Fell and colleagues (Fell et al., 2001) demonstrated a close relationship between theta and gamma frequencies with intracranial recordings at rhinal cortex and the hippocampus. The authors reanalyzed the data from (Fell et al., 2003) and showed that successful encoding is supported by transient rhinalhippocampal coupling and de-coupling in the gamma frequency range. Additionally, the analyses in the later study revealed that encoding-related rhinal-hippocampal theta coherence was correlated with changes in gamma synchronization, which supports the notion that thetamediated synchronization between rhinal and hippocampal cortices is functionally related to more transient coupling and de-coupling processes in the gamma frequency band. ${ }^{2}$

\subsection{Summary of findings from adult memory research}

Taken together, findings from adult memory research applying either fMRI or EEG measures within the subsequent memory paradigm indicate that the processes through which different aspects of a memory episode are encoded and fused into a coherent representation rely on close interactions among frontal, parietal, and mediotemporal regions. Generally, subsequent memory effects in these regions are stronger when memory formation is intentional and the memory is associative (e.g., inter-item or item-context) in nature. In comparison, the lateralization of subsequent memory effects in different brain regions seems to primarily reflect the type of to-be-remembered materials. Moreover, MTL and PFC regions both contribute to memory encoding but seem to serve different functions. The overall function of MTL regions, especially the hippocampus, consists in binding the various features of an episode into a compound representation and in consolidating this compound representation in interaction with sensory-specific and posterior-parietal association areas. In contrast, PFC regions are more involved in processes related to attention and working memory that optimize memory formation by selecting, elaborating, and organizing semantic and contextual features of the episode. Distinctions between MTL and PFC contributions to successful encoding are of special importance in the light of differences in lifespan trajectories between these regions (e.g., Raz et al., 2004; Sowell et al., 2003).

\section{Successful encoding in older adults}

Evidence of aging-related decline in various aspects of episodic memory is well established (e.g., see Dixon et al., 2004; Light, 1991; Zacks et al., 2000) for reviews. Most importantly, aging appears to compromise binding mechanisms, be it the association between content and context (e.g., Spencer and Raz, 1995), the concatenation of features into a compound memory item e.g., (Chalfonte and Johnson, 1996), or the generation of relations between different items (e.g., Li et al., 2005; Naveh-Benjamin, 2000).

\footnotetext{
${ }^{2}$ Other examples of memory related interactions between theta and gamma frequencies are reported in the case of conscious recollection as opposed to mere familiarity, assessed with a remember-know procedure (Burgess and Ali, 2002) and during the retention interval in a short-term memory task (Schack et al., 2002).
} 
(a)
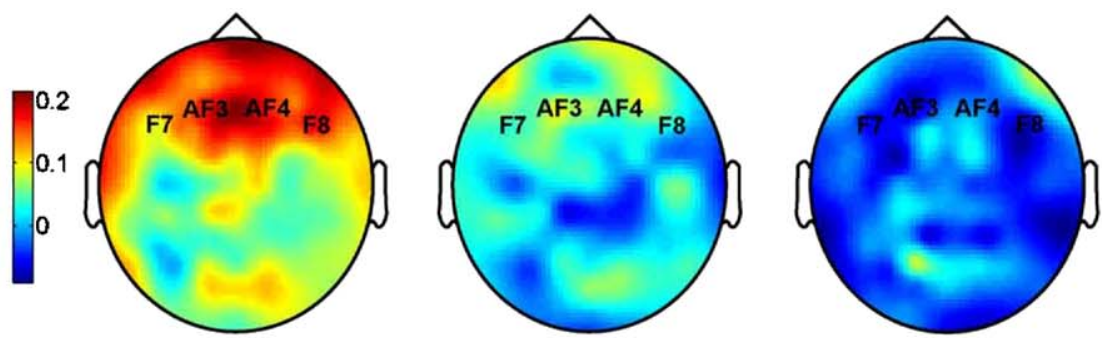

(b)
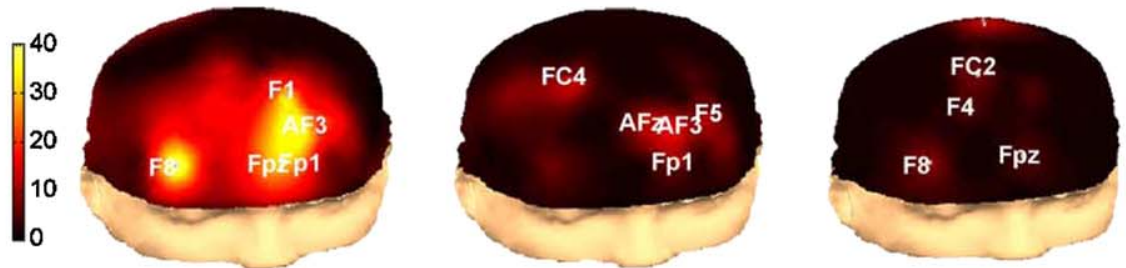

(c)

WC

F8
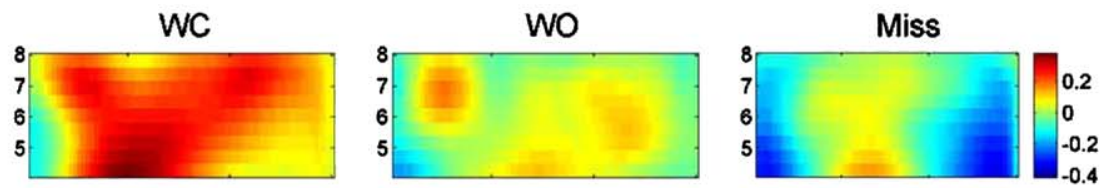

AF4
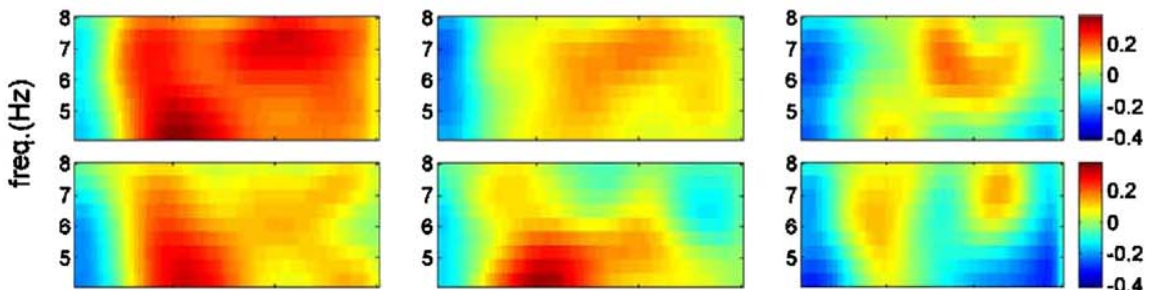

F7

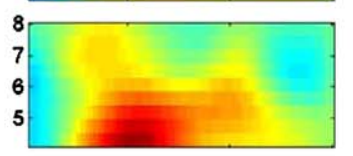

AF3
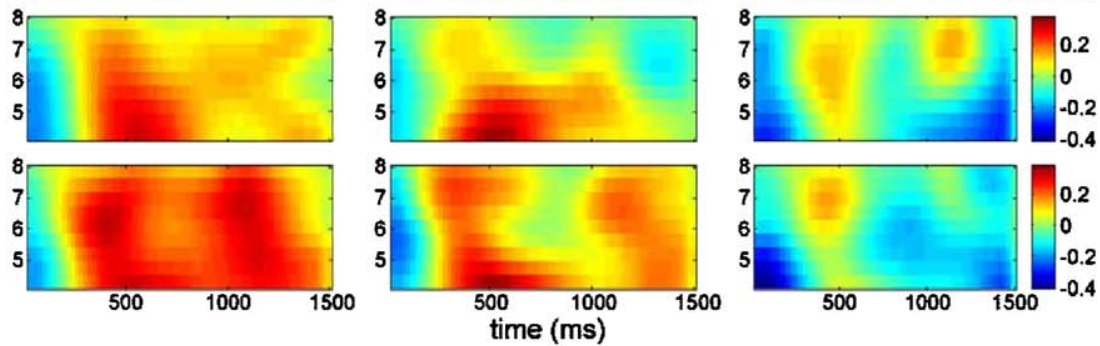

(d)
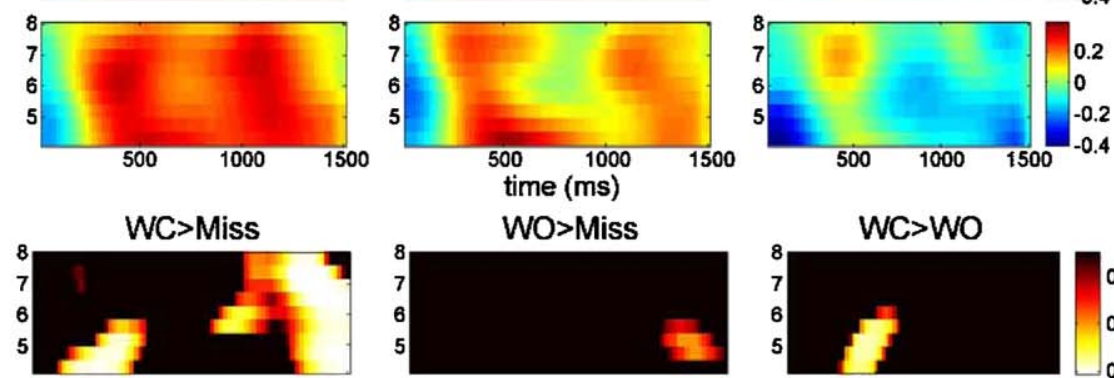

F8
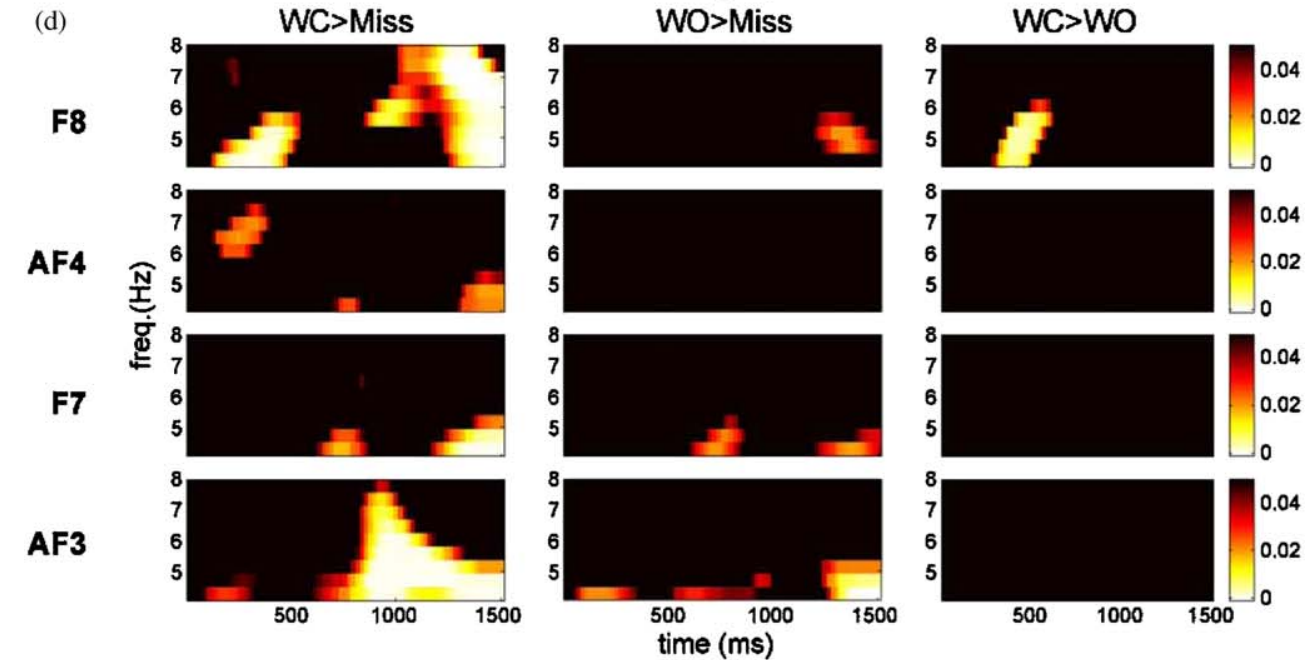

Fig. 2. Illustration of subsequent memory effects in the EEG frequency domain. Changes in local frontal theta activity predict successful remembering. (a) Mean theta power across the epoch for item-plus-context encoding condition (WC; left), item encoding condition (WO, middle), and Miss trials (right). (b) Brain regions showing significant differences in theta power for comparisons, WC $>$ Miss (left), WO $>$ Miss (middle), and WC $>$ WO (right). The scale refers to the percentage of pixels across TF space reaching $P<0.05$ significance. (c) Mean time-frequency profile of theta-band activity for four representative frontal electrodes. Values are mean $\mathrm{z}$ scores across subjects. (d) Regions of TF space showing significant differences for the three comparisons. The scale refers to $\mathrm{P}$ values; only $P$ values $<0.05$ are shown. (Adapted from Summerfield and Mangels, 2005, with permission.) 
During memory encoding, such associative binding deficits can affect the likelihood of whether an event will later be remembered. Furthermore, senescent changes in anatomy in MTL and PFC regions (e.g., Raz et al., 2004, 2005; Raz and Rodrigue, 2006) as well as declines in neuromodulation (e.g., Bäckman and Farde, 2005; Bäckman et al., 2006) are likely to affect the configuration and temporal dynamics of functional circuitries, thereby leading to age-associated differences in cortical correlates of successful memory encoding.

\subsection{Aging-related changes in brain structures and electrophysiological activity}

Neuroanatomical studies of aging have shown that brain architecture is altered in various ways as people age. The overall volume as well as gray and white matter densities in many brain regions decline, though at different rates. Other adverse age effects on the brain include an increase of ventricular size, neuronal death, loss of dendritic density, and deficient neuromodulation. These aging-related alterations do not only affect different levels of phenomena (i.e., form a neurochemical level, e.g., changes in neurotransmitter availability, up to functions of neuronal circuitries). The changes also appear differential, and sometimes nonlinear, as revealed by comparing the variations between different regions of the same brain. The results may also differ depending on whether cross-sectional or longitudinal methods were applied. For instance, in a longitudinal study on five-year change in regional brain volumes in healthy adults (Raz et al., 2004) it was observed that the caudate nucleus, the cerebellum, the hippocampus and the tertiary association cortices shrunk substantially, whereas entorhinal cortex showed minimal change, and no change was found in the primary visual cortex. Moreover, longitudinal measures of shrinkage exceeded cross-sectional estimates, showing individual differences in change across all brain regions except the inferior parietal lobule. These differences correlated across some regions, suggesting common causes in shrinkage. A concise treatment of the various structural changes on different levels in specific brain regions is beyond the scope of this paper. The interested reader may therefore be referred to recent, more detailed reviews of these topics. (e.g., Bäckman and Farde, 2005; Bäckman et al., 2006; Raz and Rodrigue, 2006; Hedden and Gabrieli, 2004; Raz, 2005).

For the memory-related structures most relevant to the current paper, it can be concluded that PFC and MTL regions exhibit differential age trajectories with respect to cortical volume (Opitz et al., 2000; Otten et al., 2001). Prefrontal regions and especially the lateral sites show steady linear decline beginning in the mid-20s. By contrast, in MTL sub-regions, differential non-linear declining patterns could be observed. For example, a MRI morphometric study (Otten et al., 2001) reported age-related shrinkage of the medial temporal lobes, with significant hippocampal decline that is accelerated after the fifth decade and minimal changes in the entorhinal cortex. Interestingly, decrease of the hippocampal volume starts later than shrinkage of the prefrontal regions.

How such extensive structural changes may be related to variations in EEG measures is currently not well understood. Nevertheless, various aging related changes for different EEG indices (e.g., spectral power, coherence) have been reported (e.g., Klimesch, 1999) For instance, with respect to EEG spectral frequencies, a common observation is a decrease in overall power with advancing age. For the alpha frequency band, an age-related reduction of the peak frequency is reported from $\sim 10.5 \mathrm{~Hz}$ in young adulthood up to $<8.5 \mathrm{~Hz}$ in people above 70 years of age (Dustman et al., 1993; Klimesch, 1999; but also see Duffy et al., 1993 for different conclusions). Such changes are typically accompanied by increasing power in higher frequencies (i.e., beta and gamma). With respect to lower frequency ranges the reports appear to be of mixed nature. While early reports (Obrist, 1954) led to the suggestion that advancing age is accompanied by power increases in delta and theta frequencies (sometimes referred to as diffuse slowing), other studies reported decrease in low frequency bands, especially for carefully selected highly healthy samples of older adults (e.g., Duffy et al., 1993). More recent reviews therefore describe decreasing power for theta and delta frequencies as indices of normal aging, while increasing slow wave activity is regarded as a sign for pathological aging (e.g., Dustman et al., 1993; Niedermeyer, 1982).

For studies that observe cortical coupling by means of measuring the coherence between signals from different electrode locations, the common observation is a higher synchronization for older compared to younger subjects (e.g., Dustman et al., 1985, 1993). Such findings are in general consistent with the notions of functional dedifferentiation with advancing age due to declining neuromodulation (e.g., Li et al., 2005; Bäckman et al., 2006) or a general loss of inhibitory connections Kinsbourne and Hicks, 1978.

\subsection{Aging and subsequent-memory effects: fMRI and PET findings}

Evidence on adult age differences in cortical processes underlying successful encoding is scarce. Morcom et al. (2003) studied event-related fMRI activation patterns underlying successful encoding in young and older adults. In line with evidence about subsequent memory effects in young adults (e.g., Kirchhoff et al., 2000; Otten et al., 2001; Wagner et al., 1999; see also Gutchess et al., 2005 below, for similar findings), the authors identified a left-lateralized network of regions including the inferior and dorsolateral prefrontal cortices as well as medio-temporal structures and notably the hippocampus that predicted successful encoding of verbal material in both age groups. However, Morcom and colleagues also noted sizeable age differences in neural activations predicting subsequent memory 
performance. Young adults exhibited larger subsequent memory effects in the anterior inferior temporal cortex. Conversely, older adults showed larger neural activity related to later memory performance than young adults in bilateral anterior PFC (BA 10), and in the left supramarginal gyrus. At least in part, these age differences were driven by so-called "subsequent forgetting effects" among young adults (i.e., forgotten $>$ remembered, see also Otten et al., 2001). Furthermore, the prefrontal subsequent memory effects were less lateralized in the older than in the young group, in agreement with other reports of reduced lateralization of neural activity with advancing adult age (Cabeza, 2002; Logan et al., 2002). Less lateralized prefrontal activation in the older adults may indicate compensatory processes due to changes in the structural organization of underlying networks (e.g., Cabeza, 2002). However, such age-related changes in the pattern of lateralization in frontal areas may also reflect a failure to efficiently recruit other cortical regions, such as MTL, during memory encoding (Logan et al., 2002), or a generalized loss of distinctiveness in processing and representation due to changes in neuromodulation and connectivity (see Bäckman et al., 2006).

Gutchess et al. (2005) obtained comparable results for pictorial material. The authors investigated whether older adults may show additional activation of frontal areas during encoding of outdoor scenes to compensate for decreased activation of MTL regions. In both age groups, regions in bilateral frontal (BA 45/46) and in higher-order visual processing areas of the ventral and dorsal stream (fusiform region) predicted subsequent memory. Relative to young adults, older adults showed less activation in the parahippocampal gyri and increased bilateral activation in the dorsolateral frontal cortex (middle frontal gyrus, BA8). Also, older adults activated a large area in the medial frontal cortex, in the region of the anterior cingulate cortex (extending from BA32 to BA10). Interestingly, this region showed a subsequent forgetting effect (forgotten $>$ remembered) among young adults, which was absent among older adults (see also Morcom et al., 2003, above). To test the hypothesis that additional frontal recruitment might be compensatory for less efficient MTL processing in the elderly, Gutchess et al. conducted correlational analyses to examine the connectivity between medial frontal, inferior frontal and parahippocampal regions. Negative relationships between parahippocampal and inferior frontal activations were found among old adults, indicating that less parahippocampal activity was associated with more inferior-frontal recruitment. This is in contrast to the results for young adults, which generally showed trends of positive correlations between frontal and medio-temporal activations (the correlation between right parahippocampal to the left inferior-frontal spot reached statistical significance).

Grady et al., 2003 applied PET to observe age-related changes in the functional and effective connectivity of several prefrontal and medio-temporal areas while participants performed two semantic encoding tasks, one referring to line drawings of common objects, and the other to words that designated those objects. Though activity in the anterior hippocampus was positively correlated with subsequent memory performance in both age groups, the regions functionally connected to the hippocampal region differed by age. For young adults, efficient recognition memory performance was supported by functional interactions between hippocampal and ventral prefrontal regions during encoding. By contrast, for older adults, efficient recognition memory performance and hippocampal activity correlated with activations in more dorsal frontal areas, regions that have been observed to serve monitoring and strategic processing functions (Petrides, 1994). Grady et al. suggested that this age-related transition from ventral to dorsal activation could index a shift from more perceptually based processes in young adults to more strategic and organizational processes in older adults. As noted by the authors, it is impossible to decide at this point whether these changes in functional connectivity predicting encoding success reflect adaptive lifespan changes in behavioral strategies or senescent changes in brain circuitry that mandate processing shifts (e.g., Gutchess et al., 2005; Logan et al., 2002; Morcom et al., 2003; see also Bäckman et al., 2006).

\subsection{Aging and subsequent-memory effects: EEG findings}

Only a few studies have investigated changes in EEG correlates of subsequent memory effects either with ERP (Friedman, 1996, 2000; cf. Friedman and Trott, 2000 for a review of the available ERP evidence up to 2000) or with oscillation-based techniques (Karrasch et al., 2004). Friedman et al. (1996) asked younger and older participants to study words under either orthographic or semantic encoding conditions. Afterwards, subjects performed either direct (stem cued recall) or indirect (word stem completion) memory tests. Memory was better under semantic than under orthographical encoding conditions in both age groups, but reliable ERP subsequent memory effects could only be found in young adults. Friedman and Trott (Friedman, 2000) investigated subsequent memory ERP differences while participants intentionally studied unrelated word pairs embedded in sentences. Recognition confidence was assessed with remember/know judgements (Gardiner, 1988; Tulving, 1985). Both age groups showed a more pronounced long-lasting positivity with an onset between 300 and $400 \mathrm{~ms}$ post-stimulus. For young adults, this positivity was more pronounced for nouns classified as "remember" than for nouns classified as "know"-items. In contrast, older adults did not show differential subsequent memory effects for "remember" and "know" items. Friedman and Trott (Friedman, 2000) suggested that the previous failure to observe ERP subsequent memory effects in older adults (i.e., Friedman et al., 1996) might reflect the incidental nature of the encoding task, as older adults may fail to spontaneously engage in elaborative encoding strategies. 
Up to date, only one study has examined age differences in oscillatory encoding activity with the subsequent memory paradigm (Karrasch et al., 2004). The authors reported adult age differences in ERS and ERD during an auditory Sternberg memory task with words as stimuli. In both young and older adults, encoding was related to ERS in the theta and alpha frequency range, whereas retrieval was related to ERS in the theta frequency as well as ERD in the alpha and beta frequency bands. Older adults showed less theta ERS during both encoding and retrieval. In addition, they showed greater alpha ERS during encoding, and smaller alpha ERD and later beta ERD during retrieval.

\section{Encoding in children}

Memory does not develop unitarily during early ontogeny, childhood, and adolescence. Implicit aspects of memory develop relatively fast and appear to be fully functional by early childhood. In contrast, explicit memory continues to improve beyond middle childhood (Kail, 2002; Murphy et al., 2003). At the neuronal level, anatomical evidence suggests that the PFC and associated neural networks undergo profound age-based changes well into adolescence, whereas MTL regions mature at considerably faster rates (e.g., Giedd et al., 1999; Sowell et al., 2003). Given the maturational time lag between medial-temporal and prefrontal cortical areas, the functional circuitries and temporal dynamics of successful memory encoding are likely to change in the transition from childhood to adulthood ( $\mathrm{Li}$ and Lindenberger, 2002). In the following, we first briefly highlight relevant neuroanatomical and electrophysiological changes from middle childhood to adulthood and then discuss open questions on investigating cortical correlates of successful memory encoding in children.

\subsection{Maturational changes in brain structures and electrophysiological activity}

Neural plasticity during corticogenesis entails the production and experience-dependent elimination of neuronal connections (Huttenlocher and Dabholkar, 1997). During brain development, the zone of maximum plasticity moves from primary sensory and motor over secondary association to prefrontal areas (Chugani et al., 1987). Computational models suggest that later maturing areas require input from earlier maturing areas to represent higher-order concepts (Shrager and Johnson, 1996). Thus, the gradual and orderly progression of the corticotrophic wave provides a chronotopic constraint for cerebral cortex organization.

Progress in neuroimaging methods has further improved our knowledge about developmental changes in the anatomy and functional dynamics of the brain. MRI studies (Paus et al., 1999; Sowell et al., 2003; Thompson et al., 2000) revealed that maturational and aging effects differ considerably across cortical regions (see also Lenroot and Giedd, 2006; Raz and Rodrigue, 2006). For instance, (Sowell et al., 2003) reported significant nonlinear decline in gray matter density with age over dorsal frontal and parietal association cortices. This decline was gradual during most periods of child development and was not fully completed until late adolescence. At the same time, there was an inverse nonlinear trend in the left posterior temporal region, where gray matter density increased rapidly from childhood up to adulthood, along with an increase in white matter volume up to middle adulthood. The overall pattern shows that the PFC regions mature at slower rates than the MTL regions.

These neuroanatomical alterations are accompanied by neurofunctional changes in cortical processing. For instance, similar to the increase in bilaterality of brain activity from adulthood to old age, bilaterality appears to decrease from childhood to early adulthood. For instance, (Holland et al., 2001) investigated brain activation patterns in children (7-18 years) when they performed a verb generation task. Though most subjects showed higher activation levels in the left than in the right hemisphere, the degree of hemispheric lateralization increased with age during child development.

With respect to electrophysiological changes, developmental EEG studies with assessments of spectral power and coherence also point to substantial changes in brain electrophysiological activity throughout child development. A recent study reported developmental changes in the EEG from 5 months to 4 years of age (Marshall et al., 2002), with decreasing spectral power at lower frequencies $(3-6 \mathrm{~Hz})$ and increasing spectral power at higher frequencies $(6-12 \mathrm{~Hz})$. Additionally, the peak frequency in infants steadily increased from 6 to $7 \mathrm{~Hz}$ at 5 months of age to $9 \mathrm{~Hz}$ at 4 years of age. With respect to synchronous EEG activity, the most pronounced maturational changes occur during the first two decades of life (Anokhin et al., 1996). During this period, one commonly observes a general reduction of EEG amplitude, along with a decrease in slow delta and theta activity, as well as a power increase in (upper) alpha and beta frequencies (Ahn et al., 1980; Harmony et al., 1990; John et al., 1980). These changes proceed at different rates in different brain regions, with higher rates of maturation at posterior sites and slower rates at anterior sites (Benninger et al., 1984; Gasser et al., 1988; Taylor and Baldeweg, 2002), continuing until late adolescence.

In addition to maturational changes in EEG spectral power, EEG coherence measures are methods for estimating changes in the coupling between different cortical sites (e.g., Barry et al., 2004; Bell and Fox, 1996; McAlaster, 1992; Thatcher, 1992, 1994). For example, the work of Thatcher $(1992,1994)$ suggests that EEG coherence exhibits periodic (i.e., 2-4 year cycles) growth spurts during child development, as measured by the velocity (first derivative) of changes in mean coherence. This pattern may point to cyclic movements between phases of synapse overproduction and phases of non-functional synapse pruning (Thatcher, 1994). Periods of major cortical reorganization, 
as assessed by such cyclic changes in corticocortical coherence, have been observed between 5 and 7 years, and again between 9 and 11 years of age. In addition, an increase in coherent long-distance anterior-posterior connections was present throughout the observed age range from 1 to 17 years, particularly in the left hemisphere. In the right hemisphere, some age-graded differentiation into short-range local coherent connections was observed.

\subsection{EEG measures of encoding in children}

Thus far, research on memory development during childhood has made relatively little contact to extant neurocognitive models of memory organization (but see Nelson et al., 2000). Rather, the dominant research strategy has been to link age-based improvements in memory performance to general information processing constructs such as short-term memory capacity, domain knowledge, memory strategies (e.g., metamemory), and processing speed (e.g., Fry and Hale, 2000). Few attempts have been made to separate these influences, to determine their relative importance and interaction, and to relate them to maturational changes in functional brain circuitry.

Perhaps due to a paucity of process-oriented research, the subsequent memory paradigm has not yet been applied to child memory research. However, a few studies have examined maturational changes in EEG measures in relation to memory functions. Bell (2002) investigated power changes in 8-months-old infants during a spatial working memory task. Spectral power was higher for correct than for incorrect responses, suggesting that working-memory related differences in cortical synchronicity patterns are already present in infancy.

Krause et al. (2001) compared 12-years-old children with young adults (21-31 years old) with respect to ERS and ERD responses in the $4-12 \mathrm{~Hz}$ frequency range during an auditory Sternberg-memory task with verbal stimuli. ERS responses in the $4-6 \mathrm{~Hz}$ theta frequency band and ERD responses in the $8-10 \mathrm{~Hz}$ alpha frequency band were delayed, but of smaller amplitude, in children than in adults. The evidence was particularly clear during memory retrieval and at anterior and central electrode locations for theta ERS, and at central and posterior electrode locations for alpha ERD. In addition, the ERD/ERS responses in the 6-8 and 8-10 theta/alpha frequency bands during encoding of the memory set and retrieval of the probe item were more similar to each other in children than those of adults. These findings have been taken to suggest that memory systems at 12 years of age have not yet fully developed and that retrieval systems may mature particularly late.

In light of profound changes in neuroanatomy (e.g., Sowell et al., 2003) and neuronal activity (e.g., Johnson, 2001; Thatcher, 1992), and given the fact that even young children are obviously able to encode and recognize objects and events in their environment, it is reasonable to assume that children's brains achieve encoding and retrieval in ways that deviate from adults (cf. Elman et al., 1996).
Therefore, subsequent memory can be expected to differ substantially between children and adults, reflecting profound differences in the dynamics of cortical networks.

\section{Conclusion and future directions}

Subsequent memory effects, or the identification of neuronal activity patterns at encoding that predict successful memory formation, provide a powerful tool to examine lifespan age differences in the neuronal organization of experience-dependent changes in behavioral repertoires. Somewhat surprisingly, though, this tool has not been frequently applied in developmental contexts. To some extent, this apparent reluctance in using the subsequent memory paradigm may reflect methodological difficulties. Different age groups tend to show different levels of recall performance under identical nominal task conditions, thereby complicating the interpretation of differences (or similarities) in subsequent memory effects. Also, when searching for EEG synchronization indices of successful encoding in different age groups, differences in basic EEG characteristics such as spectral power and amplitude need to be considered. For instance, frequency bands may need to be defined individually to account for developmental shifts in the spectrum of oscillatory activity (Klimesch, 1999).

Though these and related problems cannot be fully resolved, they can be attenuated by taking appropriate precautions in research design and data analysis. Thus, it seems worthwhile to intensify use of the subsequent memory paradigm in developmental research in order to test hypotheses about lifespan changes in the neuronal organization of learning and memory.

\subsection{Lifespan changes in subsequent memory effects: comparing PFC and MTL structures}

For young adults, the available fMRI and EEG evidence shows that encoding success is maximized through close interactions between associative binding processes primarily supported by the MTL and attentional and organizational processes primarily supported by the PFC. Thus, a useful point of departure for future lifespan work on subsequent memory effects is to gauge developmental changes in the relative contribution of these structures and the processes they support to successful encoding.

First, available evidence suggests that the more associative components, which are primarily linked to sensory processing areas and the MTL, are fully functional in middle childhood but compromised in later adulthood. Thus, we may expect that memory performance during encoding in children is supported to a larger degree by activity in the MTL and sensory structures than it is in older adults.

With respect to lifespan age differences in strategic processes during memory encoding, the situation is more complex, primarily because age-graded biological changes 
and experience interact in complex ways during ontogeny (Baltes et al., 2006b; Li and Lindenberger, 2002). Strategic processes during memory encoding serve to elaborate, organize and integrate memory contents, and are primarily supported by PFC structures and their interaction with MTL structures. Given the late maturation and early decline of the PFC, one may expect that successful encoding is less well supported by PFC activity in both children and older adults relative to young adults. For children, this results in a rather clear overall picture: Relative to young adults, MTL and sensory areas are expected to play a relatively more prominent role in supporting successful memory formation, whereas the PFC is expected to play a less prominent role. For EEG measures such differences could show up in less pronounced local frontal theta responses accompanied by less pronounced long-range theta synchronization patterns compared to adults, which would give a hint on less mature frontal-processing networks.

Unfortunately, predictions regarding subsequent memory effects in older adults are more difficult to make. The functional status of both PFC and MTL structures and their connections are compromised among older adults. It is hard to predict how the brain as a system adapts to a situation in which most major components are compromised. Second, for most domains of life, older adults and children vastly differ in the amount of task-relevant experience-related knowledge. As a consequence, older adults are more likely to retrieve world knowledge (e.g., contents from semantic memory) and past memory episodes during encoding. Therefore, successful integration of new information into existing bodies of knowledge during encoding may be particularly relevant for predicting successful memory among older adults. Given that retrieval processes during encoding are supposed to involve prefrontal areas (cf. Fletcher and Henson, 2001; Simons and Spiers, 2003 for a review), this consideration would lead to the prediction that PFC activity is more strongly related to successful encoding in older adults than in children.

\subsection{Investigating lifespan differences in neuronal organization of successful encoding}

Lifespan comparisons of cortical correlates of successful encoding may profit from experimental paradigms that systematically vary the relative demands on strategic processes (e.g., elaborative) and associative binding (see Fig. 3). Based on the above considerations, we expect the following lifespan age differences in subsequent memory effects. First, we assume that cortical correlates of successful memory encoding differ least across age groups when both strategic and associative demands are low (i.e., area A). This condition can then serve as a baseline for further comparisons.

When demands on strategic processes are low but demands on associative binding are high (Area B in Fig. 3), differences in subsequent memory effects between

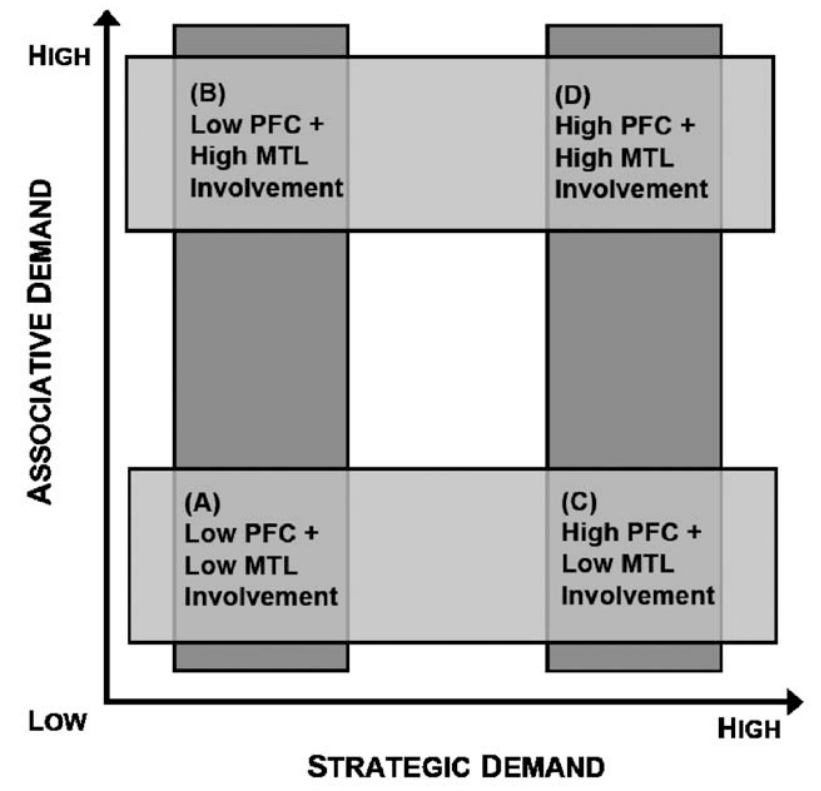

Fig. 3. Schematic representation of a taxonomy that crosses demands on associative and strategic processes during initial encoding. Experimental designs that vary both associative and strategic demands may allow researchers to examine the relative contribution of prefrontal (PFC) and medio-temporal (MTL) activity to lifespan differences in neuronal patterns of successful encoding.

children and young adults may still be small, as MTL functions are functionally mature by middle childhood. In contrast, older adults may differ from both young adults and children, reflecting the deterioration of MTL functions with advancing adult age. The precise nature of the difference is difficult to predict. One possibility is that older adults try to overcome their associative binding deficits by increasing reliance on strategic processes. In this case, we would expect that subsequent memory effects show a greater PFC involvement in older adults than in young adults and children.

A similar ambiguity exists for tasks with high demands on strategic elaboration but low demands on associative binding (Area $\mathrm{C}$ in Fig. 3). On the one hand, one may argue that subsequent memory effects should not differ much between middle childhood and old age under such conditions because the efficacy of PFC functions is low in both age groups and the MTL advantage of the children is not brought to the fore. On the other hand, older adults may again show more pronounced frontal subsequent memory effects under such conditions than children, reflecting successful attempts to integrate new information into existing bodies of knowledge. In either case, young adults are expected to show more pronounced prefrontal subsequent memory effects than children, reflecting maturational differences in PFC structures.

Finally, we expect that lifespan differences in functional networks of successful encoding will be maximized when both strategic and associative demands are high (Area D in Fig. 3). Thus, age differences in structural and functional 
brain networks activated to acquire new knowledge will be most pronounced under such conditions. Again, we assume that differences between children and young adults will primarily reflect the immaturity of children's prefrontal circuitry, whereas differences between older adults and young adults will reflect functional decrements of both PFC and MTL structures with advancing adult age, which is possibly complicated by lifelong adaptations to these decrements (e.g., compensatory recruitment) as well as a greater functional significance of retrieval operations during encoding.

\subsection{Improving the subsequent memory design}

So far, the subsequent memory paradigm has been used to identify neuronal correlates during encoding that separate items that were remembered from items that were not remembered. Items may not be remembered for a variety of reasons. For instance, they may have been poorly encoded, or they may not have been encoded at all. Poorly encoded items may be remembered when retrieval support is increased but items that have not been encoded will not profit from retrieval manipulations. Patterns of encoding activity that separate well-encoded items from poorly encoded items may differ from patterns that separate well-encoded items from not-encoded items. Setting these classes of items apart would also contribute to a more finegrained understanding of age differences in memoryrelevant processes. Therefore, it seems worthwhile to augment current paradigms with fully crossed manipulations in levels of encoding elaboration and retrieval support.

\section{References}

Ahn, H., Prichep, L., John, E.R., Baird, H., Trepetin, M., Kaye, H., 1980. Developmental equations reflect brain dysfunction. Science 210, $1259-1262$.

Anokhin, A.P., Birbaumer, N., Lutzenberger, W., Nikolaev, A., Vogel, F., 1996. Age increases brain complexity. Electroencephalography and Clinical Neurophysiology 99, 63-68.

Bäckman, L., Farde, L., 2005. The role of dopamine systems in cognitive aging. In: Cabeza, R., Nyberg, L., Park, D.C. (Eds.), The Cognitive Neuroscience of Aging. Oxford University Press, New York, pp. 58-84.

Bäckman, L., Nyberg, L., Lindenberger, U., Li, S.-C., Farde, L., 2006. The correlative triad among aging, dopamine, and cognition: current status and future prospects. Neuroscience and Biobehavioral Reviews, this issue.

Baltes, P.B., Lindenberger, U., Staudinger, U.M., 2006a. Lifespan theory in developmental psychology. In: Damon, W. (Series Ed.), \& Lerner, R.M. (Vol. Ed.), Handbook of Child Psychology: vol. 1. Theoretical Models of Human Development, sixth ed. Wiley, New York.

Baltes, P.B., Reuter-Lorenz, P., Rösler, F. (Eds.), 2006b. Lifespan Development and the Brain: The Perspective of Biocultural Coconstructivism. Cambridge University Press, New York.

Barlow, H.B., 1972. Single units and cognition: a neurone doctrine for perceptual psychology. Perception 1, 371-394.

Barry, R.J., Clarke, A.R., McCarthy, R., Selikowitz, M., Johnstone, S.J., Rushby, J.A., 2004. Age and gender effects in coherence: I. Developmental trends in normal children. Clinical Neurophysiology 115, 2252-2258.
Bell, M.A., Fox, N.A., 1996. Crawling experience is related to changes in cortical organization during infancy: Evidence from EEG coherence. Developmental Psychobiology 29, 551-561.

Bell, M.A., 2002. Power changes in infant EEG frequency bands during a spatial working memory task. Psychophysiology 39, 450-458.

Benes, F.M., Taylor, J.B., Cunningham, M.C., 2000. Convergence an plasticity of monoaminergic systems in the medial prefrontal cortex during the postnatal period: implications for the development of psychopathology. Cerebral Cortex 10, 1014-1027.

Benninger, C., Matthis, P., Scheffner, D., 1984. EEG development of healthy boys and girls. Results of a longitudinal study. Electroencephalography and Clinical Neurophysiology 57, 1-12.

Bressler, S.L., 2002. Understanding cognition through large-scale cortical networks. Current Directions in Psychological Science 11, 58-61.

Brewer, J.B., Zhao, Z., Desmond, J.E., Glover, G.H., Gabrieli, J.D.E., 1998. Making memories, brain activity that predicts how well visual experience will be remembered. Science 281, 1185-1187.

Brown, M.W., Aggleton, J.P., 2001. Recognition memory: what are the roles of the perirhinal cortex and hippocampus? Nature Reviews Neuroscience 2, 51-61.

Burgess, A.P., Ali, L., 2002. Functional connectivity of gamma EEG activity is modulated at low frequency during conscious recollection. International Journal of Psychophysiology 46, 91-100.

Cabeza, R., 2002. Hemispheric asymmetry reduction in old adults: The HAROLD model. Psychology and Aging 17, 85-100.

Canli, T., Zhao, Z., Brewer, J.B., Gabrieli, J.D.E., Cahill, L., 2000. Eventrelated activation in the human amygdale associates with later memory for individual emotional experience. Journal of Neuroscience 20, 1-5.

Chalfonte, B.L., Johnson, M.K., 1996. Feature memory and binding in young and older adults. Memory and Cognition 24, 403-416.

Chugani, H.T., Phelps, M.E., Mazziotta, J.C., 1987. Positron emission tomography study of human brain functional development. Annals of Neurology 22, 487-497.

Cycowicz, Y.M., Friedman, D., 1999. The effect of intention to learn novel, environmental sounds on the novelty $\mathrm{P} 3$ and old/new recognition memory. Biological Psychology 50, 35-60.

Daselaar, S.M., Veltman, D.J., Rombouts, S.A., Lazeron, R.H., Raaijmakers, J.G., Jonker, C., 2003. Neuroanatomical correlates of episodic encoding and retrieval in young and elderly subjects. Brain $126,43-56$.

Daselaar, S.M., Veltman, D.J., Rombouts, S.A., Raaijmakers, J.G., Jonker, C., 2003. Deep processing activates the medial temporal lobe in young but not elderly adults. Neurobiology of Aging 24, 1005-1011.

Davachi, L., Wagner, A.D., 2002. Hippocampal contributions to episodic encoding: Insights from relational and item-based learning. Journal of Neurophysiology 88, 982-990.

Desimone, R., Duncan, J., 1995. Neural mechanisms of selective visual attention. Annual Review of Neuroscience 18, 193-222.

Dixon, R.A., Wahlin, A., Maitland, S.P.etal., 2004. Episodic memory changes in late adulthood: generalizability across samples and performance indices. Memory and Cognition 32, 768-778.

Duffy, F.H., McAnulty, G.B., Albert, A.S., 1993. The pattern of agerelated differences in electrophysiological activity of healthy males and females. Neurobiology of Aging 14, 73-84.

Duncan, J., Owen, A.M., 2000. Common regions of the human frontal lobe recruited by diverse cognitive demands. Trends in Neurosciences 23, 475-483.

Dustman, R.E., La Marche, J.A., Cohn, N.B., Shearer, D.E., Talone, J.M., 1985. Power spectral analysis and cortical coupling of EEG for young and old normal adults. Neurobiology of Aging 6, 193-198.

Dustman, R.E., Shearer, D.E., Emmerson, R.Y., 1993. EEG and eventrelated potentials on normal aging. Progress in Neurobiology 41, 369-401.

Eichenbaum, H., 2000. Cortical-hippocampal networks for declarative memory. Nature Reviews Neuroscience 1, 41-50.

Elman, J.L., Bates, E.A., Johnson, M.H., Karmiloff-Smith, A., Parisi, D., Plunkett, K., 1996. Rethinking Innateness: A Connectionist Perspective on Development. MIT Press, Cambridge, MA. 
Engel, A.K., Singer, W., 2001. Temporal binding and the neural correlates of sensory awareness. Trends in Neuroscience 5, 16-25.

Fabiani, M., Karis, D., Donchin, E., 1990. Effects of mnemonic strategy manipulation in a von Restorff paradigm. Electroencephalography and Clinical Neurophysiology 75, 22-35.

Fell, J., Klaver, P., Lehnertz, K., Grunwald, T., Schaller, C., Elger, C.E., Fernández, G., 2001. Human memory formation is accompanied by rhinal-hippocampal coupling and decoupling. Nature Neuroscience 4, 1259-1264.

Fell, J., Klaver, P., Elfadil, H., Schaller, C., Elger, C.E., Fernández, G., 2003. Rhinal-hippocampal theta coherence during declarative memory formation: Interaction with gamma synchronization? European Journal of Neuroscience 17, 1082-1088.

Fernandez, G., Tendolkar, I., 2001. Integrated brain activity in medial temporal and prefrontal areas predicts subsequent memory performance: Human declarative memory formation at the system level. Brain Research Bulletin 55, 1-9.

Fernàndez, G., Brewer, J.B., Zhao, Z., Glover, G.H., Gabrieli, J.D.E., 1999a. The level of sustained enthorinal activity at study correlates with subsequent cued recall performance, a functional magnetic resonance imaging study with high acquisition rate. Hippocampus 9 , $35-44$.

Fernàndez, G., Effern, A., Grunwald, T., Pezer, N., Lehnertz, K., Dümpelmann, M., VanRoost, D., Elger, C.E., 1999b. Real-time tracking of memory formation in the human rhinal cortex and hippocampus. Science 285, 1582-1585.

Fletcher, P.C., Henson, R.N.A., 2001. Frontal lobes and human memory: Insights from functional neuroimaging. Brain 124, 849-881.

Friedman, D., 1990. ERPs during continuous recognition memory for words. Biological Psychology 30, 61-87.

Friedman, D., 2000. Event-related potential investigations of memory and aging. Biological Psychology 54, 175-206.

Friedman, D., Johnson Jr., R., 2000. Event-related potential (ERP) studies of memory encoding and retrieval: A selective review. Microscopy Research and Technique 51, 6-28.

Friedman, D., Trott, C., 2000. An event-related potential study of encoding in young and older adults. Neuropsychologia 38, 542-557.

Friedman, D., Ritter, W., Snodgrass, J.G., 1996. ERPs during study as a function of subsequent direct and indirect memory testing in young and old adults. Cognitive Brain Research 4, 1-13.

Fry, A.F., Hale, S., 2000. Relationships among processing speed, working memory, and fluid intelligence in children. Biological Psychology 54, $1-34$.

Fuster, J.M., 1995. Memory in the Cerebral Cortex-An empirical Approach to Neural Networks in the Human and Nonhuman Primate. MIT Press, Cambridge, MA.

Gardiner, J.M., 1988. Functional aspects of recollective experience. Memory and Cognition 16, 309-313.

Gasser, T., Verleger, R., Bächer, P., Sroka, L., 1988. Development of the EEG of school-age children and adolescents. Electroencephalography and Clinical Neurophysiology 69, 91-99.

Gathercole, S.E., 1998. The development of memory. Journal of Child Psychology and Psychiatry 39, 3-27.

Giedd, J.N., Blumenthal, J., Jeffries, N.O., Castellanos, F.X., Liu, H., Zijdenbos, A., Paus, T., Evans, A.C., Rapoport, J.L., 1999. Brain development during childhood and adolescence: a longitudinal MRI study. Nature Neuroscience 2, 861-863.

Givens, B.S., Olton, D.S., 1990. Cholinergic and GABAergic modulation of medial septal area: effect on working memory. Behavioral Neuroscience 104, 849-855.

Golby, A.J., Poldrack, R.A., Brewer, J.B., Spencer, D., Desmond, J.E., Aron, A.P., Gabrieli, J.D.E., 2001. Material-specific lateralization in the medial temporal lobe and prefrontal cortex during memory encoding. Brain 124, 1841-1854.

Grady, C.L., McIntosh, A.R., Craik, F.I.M., 2003. Age-related differences in the functional connectivity of the hippocampus during memory encoding. Hippocampus 13, 527-586.
Grady, C.L., McIntosh, A.R., Rajah, M.N., Beig, S., Craik, F.I.M., 1999. The effects of age on the neural correlates of episodic encoding. Cerebral Cortex 9, 805-814.

Greenstein, Y.P., Pavlides, C., Winson, J., 1988. Long-term potentiation in the dentate gyrus is preferentially induced at theta rhythm periodicity. Brain Research 438, 331-334.

Gruber, T., Tsivilis, D., Montaldi, D., Müller, M.M., 2004. Induced gamma band responses: an early marker of memory encoding and retrieval. NeuroReport 15, 1837-1841.

Guo, C., Voss, J.L., Paller, K.A., 2005. Electrophysiological correlates of forming memories for faces, names, and face-name pairs. Cognitive Brain Research 22, 152-164.

Gutchess, A.H., Welsh, R.C., Hedden, T., Bangert, A., Minear, M., Liu, L.L., Park, D.C., 2005. Aging and the neural correlates of successful picture encoding: Frontal activations compensate for decreased medialtemporal activity. Journal of Cognitive Neuroscience 17, 84-96.

Harmony, T., Marosi, E., Díaz de León, A.E., Becker, J., Fernández, T., 1990. Effect of sex, psychosocial disadvantages and biological risk factors on EEG maturation. Electroencephalography and Clinical Neurophysiology 6, 482-491.

Hedden, T., Gabrieli, J.D.E., 2004. Insights into the ageing mind: a view from cognitive neuroscience. Nature Reviews Neuroscience 5, 87-96.

Holland, S.K., Plante, E., Byars, A.W., Strawsburg, R.H., Schmithorst, V.J., Ball Jr., W.S., 2001. Normal fMRI brain activation patterns in children performing a verb generation task. NeuroImage 14, 837-843.

Huerta, P.T., Lisman, J.E., 1993. Heightened synaptic plasticity of hippocampal CA1 neurons during a cholinergically induced rhythmic state. Nature 364, 723-725.

Huttenlocher, P.R., Dabholkar, A.S., 1997. Regional differences in synaptogenesis in human cerebral cortex. Journal of Comparative Neurology 387, 167-178.

Jackson, O., Schacter, D.L., 2004. Encoding activity in anterior medial temporal lobe supports subsequent associative recognition. NeuroImage 21, 456-462.

Jensen, O., 2001. Information transfer between rhythmically coupled networks: Reading the hippocampal phase code. Neural Computation 13, 2743-2761.

John, E.R., Ahn, H., Prichep, L., Trepetin, M., Brown, D., Kaye, H., 1980. Developmental equations for the electroencephalogram. Science 210, $1255-1258$.

Johnson, M.H., 2001. Functional brain development in humans. Nature Reviews Neuroscience 2, 475-483.

Kail, R., 2002. Developmental change in proactive interference. Child Development 73, 1703-1714.

Karrasch, M., Laine, M., Rapinoja, P., Krause, C.M., 2004. Effects of normal aging on event-related desynchronization/synchronization during a memory task in humans. Neuroscience Letters 366, 18-23.

Kelley, W.M., Miezin, F.M., McDermott, K.B., Buckner, R.L., Raichle, M.E., Cohen, N.J., Snyder, A.Z., Petersen, S.E., 1998. Hemispheric specialization in human dorsal frontal cortex and medial temporal lobe for verbal and nonverbal memory encoding. Neuron 20, 927-936.

Kinsbourne, M., Hicks, R.E., 1978. Functional cerebral space: A model for overflow, transfer and interference effects in human performance: A tutorial review. In: Requin, J. (Ed.), Attention and Performance VII. Lawrence Erlbaum, Hillsdale, NJ.

Kirchhoff, B.A., Wagner, A.D., Maril, A., Stern, C.E., 2000. Prefrontaltemporal circuitry for episodic encoding and subsequent memory. Journal of Neuroscience 20, 6173-6180.

Klimesch, W., 1996. Memory processes, brain oscillations and EEG synchronization. International Journal of Psychophysiology 24, 61-100.

Klimesch, W., 1999. EEG alpha and theta oscillations reflect cognitive and memory performance: A review and analysis. Brain Research Reviews 29, 169-195.

Klimesch, W., Doppelmayr, M., Russegger, H., Pachinger, T., 1996. Theta band power in the human scalp EEG and the encoding of new information. NeuroReport 7, 1235-1240. 
Kounios, J., Smith, R.W., Yang, W., Bachman, P., D'Esposito, M., 2001. Cognitive association formation in human memory revealed by spatiotemporal brain imaging. Neuron 29, 297-306.

Krause, C.M., Salminen, P.-A., Sillanmäki, L., Holopainen, I.E., 2001. Event-related desynchronization and synchronization during a memory task in children. Clinical Neurophysiology 112, 2233-2240.

Larson, J., Wong, D., Lynch, G., 1986. Patterned stimulation at the theta frequency is optimal for the induction of hippocampal long-term potentiation. Brain Research 368, 347-350.

Lee, A.C.H., Robbins, T.W., Owen, A.M., 2000. Episodic memory meets working memory in the frontal lobes: functional-neuroimaging studies of encoding and retrieval. Critical Reviews in Neurobiology 14, 165-198.

Lenroot, R.K., Giedd, J.N., 2006. Brain development and adolescents: insights from anatomical magnetic resonance imaging. Neuroscience and Biobehavioral Reviews, this issue.

Li, S.-C., Lindenberger, U., 2002. Coconstructed functionality instead of functional normality. Behavioral and Brain Sciences 25, 761-762.

Li, S.-C., Naveh-Benjamin, M., Lindenberger, U., 2005. Aging neuromodulation impairs associative binding: a neurocomputational account. Psychological Science 16, 445-450.

Light, L.L., 1991. Memory and Aging - 4 hypotheses in search of data. Annual Review of Psychology 42, 333-376.

Lisman, J.E., Idiart, M.A.P., 1995. Storage of $7 \pm 2$ short-term memories in oscillatory subcycles. Science 267, 1512-1515.

Logan, J.M., Sanders, A.L., Snyder, A.Z., Morris, J.C., Buckner, R.L., 2002. Under-recruitment and nonselective recruitment: dissociable neural mechanisms associated with aging. Neuron 28, 827-840.

Mangels, J.A., Picton, T.W., Craik, F.I.M., 2001. Attention and successful episodic encoding: an event-related potential study. Cognitive Brain Research 11, 77-95.

Marshall, P.J., Bar-Haim, Y., Fox, N.A., 2002. Development of EEG from 5 months to 4 years of age. Clinical Neurophysiology 113, 1199-1208.

McAlaster, R., 1992. Postnatal cerebral maturation in Downs-syndrome children - A developmental EEG coherence study. International Journal of Neuroscience 65, 221-237.

Miller, R., 1991. Cortico-hippocampal Interplay and the Representation of Contexts in the Brain. Springer, Berlin.

Miller, E.K., Cohen, J.D., 2001. An integrative theory of prefrontal cortex function. Annual Reviews of Neuroscience 24, 167-202.

Mölle, M., Marshall, L., Fehm, H.L., Born, J., 2002. EEG theta synchronization conjoined with alpha desynchronization indicate intentional encoding. European Journal of Neuroscience 15, 923-928.

Morcom, A.M., Good, C.D., Frackowiak, R.S.J., Rugg, M.D., 2003. Age effects on the neural correlates of successful memory encoding. Brain 126, 213-229.

Münte, T.F., Heinze, H.J., Scholz, M., Kunkel, H., 1988. Effect of a cholinergic nootropic (WEB $1881 \mathrm{FU}$ ) on event-related potentials recorded in incidental and intentional memory tasks. Neuropsychobiology 19, 158-168.

Murphy, K., McKone, E., Slee, J., 2003. Dissociation between implicit and explicit memory in children: the role of strategic processing and the knowledge base. Journal of Experimental Child Psychology 84, 124-165.

Naveh-Benjamin, M., 2000. Adult age differences in memory performance: Tests of an associative deficit hypothesis. Journal of Experimental Psychology-Learning Memory and Cognition 26, 1170-1187.

Nelson, C.A., Monk, C.S., Lin, J., Carver, L.J., Thomas, K.M., Truwit, C.L., 2000. Functional neuroanatomy of spatial working memory in children. Developmental Psychology 36, 109-116.

Niedermeyer, E., 1982. EEG and old age. In: Niedermeyer, E., Lopes Da Silva, F. (Eds.), Electroencephalography. Basic Principles, Clinical Applications, and Related Fields. Urban und Schwarzenberg, Baltimore/Munich.

Nolde, S.F., Johnson, M.K., Raye, C.L., 1998. The role of prefrontal cortex during tests of episodic memory. Trends in Cognitive Science 2, 399-406.
Nunez, P.L., 2000. Toward a quantitative description of large-scale neocortical dynamic function and EEG. Behavioral Brain Science 23, $371-432$.

O'Reilly, R.C., Norman, K.A., 2002. Hippocampal and neocortical contributions to memory: Advances in the complementary learning systems framework. Trends in Cognitive Science 6, 505-510.

O’Reilly, R.C., Rudy, J.W., 2001. Conjunctive representations in learning and memory: principles of cortical and hippocampal function. Psychological Review 108, 311-345.

Obrist, W.D., 1954. The electroencephalogram of normal aged adults. Electroencephalography and Clinical Neurophysiology 6, 235-244.

Opitz, B., Mecklinger, A., Friederici, A.D., 2000. Functional asymmetry of human prefrontal cortex: Encoding and retrieval of verbally and nonverbally coded information. Learning and Memory 7, 85-96.

Otten, L.J., Henson, R.N.A., Rugg, M.D., 2001. Depth of processing effects on neural correlates of memory encoding: relationship between findings from across- and within-task comparisons. Brain 124, 399-412.

Otten, L.J., Henson, R.N.A., Rugg, M.D., 2002. State-related and itemrelated neural correlates of successful memory encoding. Nature Neuroscience 5, 1339-1344.

Paller, K.A., Wagner, A.D., 2002. Observing the transformation of experience into memory. Trends in Cognitive Science 6, 93-102.

Paller, K.A., Kutas, M., Mayes, A.R., 1987. Neural correlates of encoding in an incidental learning paradigm. Electroencephalography and Clinical Neurophysiology 67, 360-371.

Pandya, D.N., Yeterian, E.H., 1996. Comparison of prefrontal architecture and connections. Philosophical Transactions of the Royal Society of London Series B-Biological Sciences 351, 1423-1432.

Paus, T., Zijdenbos, A., Worsley, K., Collins, D.L., Blumenthal, J., Giedd, J.N., Rapoport, J.L., Evans, A.C., 1999. Structural maturation of neural pathways in children and adolescents: in vivo study. Science 283, 1908-1911.

Petrides, M., 1994. Frontal lobes and working memory, evidence from investigations of the effects of cortical excisions in nonhuman primates. In: Boller, F., Grafman, J. (Eds.), Handbook of Neuropsychology, vol. 10. Elsevier Science, Amsterdam, pp. 59-81.

Raz, N., 2005. The aging brain observed in vivo. Differential changes and their modifiers. In: Cabeza, R., Nyberg, L., Park, D.C. (Eds.), The Cognitive Neuroscience of Aging. Oxford University Press, New York, pp. $58-84$.

Raz, N., Rodrigue, K.M., 2006. Differential aging of the brain: patterns, cognitive correlates and modifiers. Neuroscience and Biobehavioral Reviews, this issue.

Raz, N., Rodrigue, K., Head, D., Kennedy, K., Acker, J., 2004. Differential aging of the medial temporal lobe: a study of a five-year change. Neurology 62, 433-439.

Raz, N., Lindenberger, U., Rodrigue, K.M., Kennedy, K.M., Head, D., Williamson, C.D., Gerstorf, D., Acker, J.D., 2005. Regional brain changes in aging healthy adults: General trends, individual differences and modifiers. Cerebral Cortex doi:10.1093/cercor/bhi044.

Sanquist, T.F., Rohrbaugh, J.W., Syndulko, K., Lindley, D.B., 1980. Electrocortical signs of levels of processing, perceptual analysis and recognition memory. Psychophysiology 17, 568-576.

Schack, B., Vath, N., Petsche, H., Geissler, H.G., Möller, E., 2002. Phasecoupling of theta-gamma EEG rhythms during short-term memory processing. International Journal of Psychophysiology 44, 143-163.

Scoville, W.B., Milner, B., 1957. Loss of recent memory after bilateral hippocampal lesions. Journal of Neurology Neurosurgery and Psychiatry $20,11-21$.

Sederberg, P.B., Kahana, M.J., Howard, M.W., Donner, E.J., Madsen, J.R., 2003. Theta and gamma oscillations during encoding predict subsequent recall. Journal of Neuroscience 26, 10809-10814.

Shrager, J., Johnson, M.H., 1996. Dynamic plasticity influences the emergence of function in a simple cortical array. Neural Networks 9, 111-1129.

Simons, J.S., Spiers, H.J., 2003. Prefrontal and medial temporal lobe interactions in long-term memory. Nature Reviews Neuroscience 4, 637-648. 
Sowell, E.R., Peterson, B.S., Thompson, P.M., Welcome, S.E., Henkenius, A.L., Toga, A.W., 2003. Mapping cortical change across the human life span. Nature Reviews Neuroscience 6, 309-315.

Spencer, W.D., Raz, N., 1995. Differential effects of aging on memory for content and context: A meta-analysis. Psychology and Aging 10, 527-539.

Squire, L.R., 1987. Memory and Brain. Oxford University Press, New York.

Stebbins, G.T., Carrillo, M.C., Dorfman, J., Dirksen, C., Desmond, J.E., Turner, D.A., Bennett, D.A., Wilson, R.S., Glover, G., Gabrieli, J.D.E., 2002. Aging effects on memory encoding in the frontal lobes. Psychology and Aging 17, 44-55.

Strange, B.A., Otten, L.J., Josephs, O., Rugg, M.D., Dolan, R.J., 2002. Dissociable human perirhinal, hippocampal, and parahippocampal roles during verbal encoding. Journal of Neuroscience 523-528.

Summerfield, C., Mangels, J.A., 2005. Coherent theta-band activity predicts item-context binding during encoding. NeuroImage 24, 692-703.

Suzuki, W.A., 1999. The long and the short of it: memory signals in the medial temporal lobe. Neuron 24, 295-298.

Tallon-Baudry, C., Bertrand, O., 1999. Oscillatory gamma activity in humans and its role in object representation. Trends in Cognitive Science 3, 151-162.

Taylor, M.J., Baldeweg, T., 2002. Application of EEG, ERP and intracranial recordings to the investigation of cognitive functions in children. Developmental Science 5, 318-334.

Thatcher, R.W., 1992. Cyclic cortical reorganisation during early childhood. Brain Cognition 20, 24-50.

Thacher, R.W., 1994. Cyclic cortical reorganization: origins of human cognitive development. In: Dawson, G., Fischer, K.W. (Eds.), Human Behavior and the Developing Brain. Guilford, New York, pp. 232-266.

Thompson, P.M., Giedd, J.N., Woods, R.P., MacDonald, D., Evans, A.C., Toga, A.W., 2000. Growth patterns in the developing brain detected by using continuum mechanical tensor maps. Nature 404, 190-193.
Tulving, E., 1983. Elements of Episodic Memory. Oxford University, Oxford.

Tulving, E., 1985. Memory and consciousness. Canadian Psychologist 26, $1-12$.

Tulving, E., Kapur, S., Craik, F.I.M., Moscovitch, M., Houle, S., 1994 Hemispheric encoding/retrieval asymmetry in episodic memory: Positron emission tomography findings. Proceedings of the National Academy of Sciences 91, 2016-2020.

Varela, F., Lachaux, J.P., Rodriguez, E., Martinerie, J., 2001. The brainweb: Phase synchronization and large-scale integration. Nature Reviews Neuroscience 2, 229-239.

Wagner, A.D., Koutstaal, W., Schacter, D.L., 1999. When encoding yields remembering: Insights from event-related neuroimaging. Philosophical Transactions of the Royal Society of London Series B-Biological Sciences 354, 1307-1324.

Wagner, A.D., Poldrack, R.A., Eldridge, L.L., Desmond, J.E., Glover, G.H., Gabrieli, J.D., 1998a. Material-specific lateralisation of prefrontal activation during episodic encoding and retrieval. NeuroReport 9, 3711-3717.

Wagner, A.D., Schacter, D.L., Rotte, M., Koutstaal, W., Maril, A., Dale, A.M., Buckner, R.L., 1998b. Building memories: remembering and forgetting of verbal experiences as predicted by brain activity. Science 281, 1188-1191.

Weiss, S., Rappelsberger, P., 2000. Long-range EEG synchronization during word encoding correlates with successful memory performance. Cognitive Brain Research 9, 299-312.

Weyerts, H., Tendolkar, I., Smid, H.G.O., Heinze, H.J., 1997. ERPs to encoding and recognition in two different inter-item association tasks. Neuroreport 8, 1583-1588.

Zacks, R.T., Hasher, L., Li, K.Z.H., 2000. Human memory. In: Salthouse, T.A., Craik, F.I.M. (Eds.), Handbook of Aging and Cognition. 2nd ed. Lawrence Erlbaum, Mahwah, NJ, pp. 293-357.

Zeineh, M.M., Engel, S.A., Thompson, P.M., Bookheimer, S.Y., 2003. Dynamics of the hippocampus during encoding and retrieval of facename pairs. Science 299, 577-580. 